\title{
Body-object interaction effect in word recognition and its relationship with screen time in Chinese children
}

\author{
Zhengye $\mathrm{Xu}^{1}$ (1) $\cdot$ Duo Liu' ${ }^{1}$
}

Accepted: 2 December 2021

(c) The Author(s), under exclusive licence to Springer Nature B.V. 2021

\begin{abstract}
A sample of 144 s- and 150 fourth-grade Chinese children was recruited to investigate the influence of body-object interactions (BOIs) on word recognition, i.e., how easily they could interact physically with each word's referent. The moderation on this relationship of children's screen time for entertainment purposes (i.e., the viewing or use of any device with a screen) was also examined. In a lexical decision task, the children were asked to judge whether each item was a real Chinese word. Each real word was assigned a BOI rating score. Model analysis showed that the BOI rating was a significant predictor of the children's word recognition performances. The children recognized the words with higher BOI ratings at higher accuracy rates and higher response speeds more than the words with lower BOI ratings, showing a BOI effect. These results suggest an involvement of sensorimotor information in processing concepts. As well, the results showed a moderating effect of screen time on the BOI effect. With the increase of screen time, the BOI effect was reduced in terms of response speed. Moreover, the influence of the screen time on the BOI effect was larger in the second graders than in the fourth graders.
\end{abstract}

Keywords Bodily interactions · Concept construction · Digital tools · Lexical meaning $\cdot$ Sensorimotor representation $\cdot$ Word recognition

\section{Introduction}

A rating of body-object interactions (BOIs) reflects the ease with which a human body can interact physically with word referents (Siakaluk et al., 2008a, 2008b). There is recent evidence that word recognition is facilitated if words have high BOI ratings, more than if they have low ratings. This advantage of words with high BOI ratings, named the BOI effect, has been revealed in studies across alphabetic

\section{Duo Liu}

duoliu@eduhk.hk

1 Department of Special Education and Counselling, The Education University of Hong Kong, No. 10 Lo Ping Road, Tai Po, N.T., Hong Kong 
languages (e.g., Tillotson et al., 2008; Tousignant \& Pexman, 2012). The BOI effect demonstrates the involvement of sensorimotor representations, which are derived from bodily interactions with objects in the world, in the acquisition and processing of conceptual meaning (Barsalou, 2008; Pecher \& Zwaan, 2005; Wilson, 2002). However, the BOI effect has seldom been investigated in the Chinese language, in which body parts are critical for expressing both concrete and abstract concepts ( $\mathrm{Yu}$, 2009). The BOI effect on children's word reading has been found in a few studies (Inkster et al., 2016; Wellsby \& Pexman, 2014), but these adopted the BOI scores rated by adults. Given their distinctive daily routines, children should have BOI patterns that are different from those of adults. Thus, the BOI ratings from adults might obstruct examinations of the BOI effect in children. Therefore, in the present study, the BOI ratings from children were used to investigate the BOI effect in Chinesespeaking children from Mainland China.

Previous studies of the BOI effect focused on the association between sensorimotor representations and concept processing (Siakaluk et al., 2008a, 2008b; Tillotson et al., 2008). Little attention has been paid to possible factors that may impact this association. To address this gap, the current study focused on one of these possible factors, screen time, i.e., the viewing or use of any device with a screen (Sweetser et al., 2012). A relationship between screen time and children's concept-processing abilities has been reported in multiple studies (Hisrich \& Blanchard, 2009; Lauricella et al., 2015; Levy, 2009). As well, it is worth noting that, in a digital world, bodily interactions with objects can also be influenced by screen time. The prevalence of children's use of digital tools results in decreasing bodily interactions with objects in the physical world (Hingle \& Kunkel, 2012). Objects that are presented on digital tools are pre-made two-dimensional images, which differ from three- or more-dimensional objects in the real world (Barr, 2013). Moreover, digital tools focus on the visual and auditory modalities; object-related information from other modalities, such as olfaction and gustation, may be limited in screen time (Minogue \& Jones, 2006; Schönborn et al., 2011). It is possible that the outcome of these changing interactions between the body and objects could lead to a moderating role of screen time in the association between BOI ratings and word recognition. To investigate this assumption, the current study investigated (a) the association between the child-rated BOI and word recognition in Chinese; and (b) the possible moderating role of screen time in this association. The results can help us to gain a more comprehensive understanding of the BOI effect in word recognition, and give related suggestions for concept acquisition in the digital world.

\section{BOI effect on word recognition in alphabetic languages}

In alphabetic languages, the facilitating BOI effect in word recognition has been reported repeatedly in lexical decision tasks, phonological lexical decision tasks, and semantic categorization tasks performed by adults (Siakaluk et al., 2008a, 2008b; Tillotson et al., 2008; Wellsby et al., 2011). This facilitating effect illustrates that the meanings of concepts are generated, at least partly, from bodily interactions with corresponding referents (Barsalou, 2008; Dove, 2016). Specifically, bodily 
interactions with the objects of a concept (e.g., strawberry) are processed initially in modality-specific memory systems (e.g., visual, taste, and olfactory systems). Then, these bodily interactions with objects in different modalities produce corresponding sensorimotor representations, which can be integrated further into the semantic aspect of literacy knowledge to enrich the meanings of concepts (Louwerse, 2018).

It is assumed that more sensorimotor representations lead to stronger feedback on semantic units (Barsalou, 2008), which can benefit the retrieval of the related orthographic and phonological units in the mental lexicon (Harm \& Seidenberg, 2004). As a result, word recognition performance can be improved (Hino \& Lupker, 1996; Siakaluk et al., 2008a, 2008b). This assumption was evident from a study of English-speaking adults (Siakaluk et al., 2008a, 2008b). To illustrate, the study measured the BOI effect in the semantic categorization task (i.e., if words were easily imageable) and in the semantic lexical decision task (i.e., if an item was a word; if it was, the participants had to decide if it was easily imageable). The results of the latency analysis showed that the magnitude of the BOI effect was larger in the semantic lexical decision task, which requires more semantic feedback relative to the semantic categorization task.

\section{BOI effect on word recognition in Chinese}

Research on the BOI effect in Chinese is still scant. As in alphabetic languages, conceptual knowledge in the Chinese language can be acquired from sensorimotor modalities through individuals' bodily interactions with referents in the world (Gibbs, 1999). For example, after gaining some bodily interactions with balls, Chinese children can summarize the same perceptual features (e.g., shape) of individual balls to widen the perceptual representation of the concept ball, resulting in benefits for acquiring and processing the concept (Barsalou, 2008; Li et al., 2007).

Moreover, in addition to concrete concepts, abstract concepts can be expressed by concrete objects/events in the Chinese language. In particular, it is common to use body-part terms to express abstract concepts (Yu, 2002). For example, 手足/ shou $3 \mathrm{zu} 2 /$ uses the concepts 手 (hand) and 足 (foot), which are two critical parts of the body, to express the meaning of sibling. The hair, i.e., 发/fa4/, is associated with anger or rage. For instance, the words 令人发指/ling 4 ren2 fa4 zhi3/ (make-one'shair-point) and 怒发冲冠/nu4 fa4 chong1 guan1/ (angry-hair-push-hat) indicate extreme anger. Many emotion concepts are expressed by the terms of head, face, eyebrows, eyes, and mouth in Chinese (Yu, 2009).

In addition, internal body parts (i.e., inner organs) are used to express abstract concepts in Chinese. For instance, the concept gallbladder, i.e., 胆/dan3/, is fundamentally related to courage. The words 胆大/dan3 da4/ (gallbladder-big) and 胆小 /dan3 xiao3/ (gallbladder-small) are used to represent bold and timid, respectively. The concept heart, i.e., 心/xin1/, is conceptualized as the seat or container for emotion in general. The words 开心/kai1 xin1/ (open-heart) and 放心/fang4 xin1/ (lay down-heart) represent the meanings of happy and feeling relieved, respectively. Although the current study was concerned with concrete concepts, the critical role of body parts in abstract concepts gives rise to a strong connection between the 
bodily interactions and meanings of concepts (Pritzker, 2003; Yu, 2009). Thus, it is reasonable to assume the existence of a BOI effect in the Chinese language.

\section{BOI effect on children's word recognition}

A few developmental studies have explored the BOI effect and lent support for the influence of bodily interactions with referents on children's word recognition (Inkster et al., 2016; Wellsby \& Pexman, 2014). Specifically, a study in English (Wellsby \& Pexman, 2014), using the BOI rating from adults (Tillotson et al., 2008), measured the BOI effect in children aged 6-9 years. This study found that only children above the age of eight years showed a significant BOI effect, but younger children did not. The authors' interpretation of these findings was that the younger children's sensorimotor experiences about referents of concepts are not enough; the corresponding sensorimotor representations fail to interact efficiently with linguistic symbols in the mental lexicon.

However, opposite results were reported in another study (Inkster et al., 2016), in which the BOIs of words were rated by the participants' parents, from the perspectives of their children. Inkster et al. (2016) revealed that the facilitating BOI effect was also significant in children younger than eight (i.e., six- and seven-year-olds). These inconsistent findings in previous studies (i.e., Inkster et al., 2016; Wellsby \& Pexman, 2014) highlight the role of individuals rating words in the BOI effect. It should be noted that, since adults and children have different daily routines, they should have different bodily interactions with an object. For example, children have more interactions with toys than adults do, leading to higher BOI ratings of concepts regarding toys (e.g., doll and lego). In addition, although Inkster et al. (2016) utilized BOI ratings made by the participants' parents, this still did not reflect the complete picture of the children's bodily interactions with objects. The BOI effect in children should be investigated further, as the findings of the prior work (e.g., Inkster et al., 2016; Wellsby \& Pexman, 2014) might have been affected by the BOI ratings from adults.

Hence, to usie a more direct approach to investigate the BOI effect in children, the participants in the current study were asked to complete a task in which they rated the BOI values of words by themselves, after completing a task examining the BOI effect on word recognition. Different from the previous studies that used a dichotomy method to categorize words, (i.e., high and low BOI words; Inkster et al., 2016; Wellsby \& Pexman, 2014), which did not take into account the variance within these two groups, linear mixed models (LMMs) were adopted in the current study. Accordingly, it was possible to consider not only the individual differences of the experimental words but also those of the participants (Luke, 2017).

In addition, with the child-rated BOIs, the current study explored the role of age in the BOI effect; no consistent conclusions were reached about this in either of the previous developmental studies (i.e., Inkster et al., 2016; Wellsby \& Pexman, 2014). In Mainland China, children's formal literacy starts in Grade 1, but the learning focus does not transform to characters and words from Pinyin (i.e., a phonemic coding approach) until the end of Grade 1 (Shen \& Bear, 2000). As mentioned before, 
the facilitating BOI effect on word recognition is assumed as a result of the enrichment of the semantic representation, relating to the integration between sensorimotor experiences and linguistic knowledge (Louwerse \& Jeuniaux, 2010). Since Chinese children as young as first graders may not have enough linguistic knowledge to reflect the BOI effect on word recognition, the current study focused on children in higher grades.

Children in Grades 2 and 4, who are respectively at the beginning and middle stages of literacy acquisition (Chung \& Leung, 2008), are good targets for investigating the role of age in the BOI effect in Chinese children. Children in these two grades were chosen because they were assumed to have learned enough Chinese characters to ensure they were able to complete the word-recognition task in this study according to the instructions. As well, these two age groups differed sufficiently in the magnitude of their linguistic knowledge and sensorimotor experiences. Specifically, children in Grade 4 should have more developed linguistic knowledge and accumulated sensorimotor experiences (Antonucci \& Alt, 2011; Carlisle, 2000), which can facilitate the connection between verbal and nonverbal information (Barsalou, 2008; Loeffler et al., 2016). Hence, it was expected that larger BOI effects would be observed in fourth graders, who have stronger connections between linguistic knowledge and sensorimotor experiences (Wilson, 2002).

\section{Possible influence of screen time on BOI in children}

In recent years, children's lives have experienced an incremental shift with the increase of screen time, which is defined as the viewing or use of any device with a screen, such as a TV, DVD, video game, computer, tablet, or smartphone (Sweetser et al., 2012). There have been reports of a relationship between screen time and early literacy development (Hillman \& Marshall, 2009; Hisrich \& Blanchard, 2009; McManis \& Gunnewig, 2012; van der Kooy-Hofland et al., 2012). Although some benefits of high-quality screen time have been identified (Neumann, 2014; Shamir \& Korat, 2007), excessive screen time has been associated with a number of deleterious cognitive and academic outcomes (Dias et al., 2016; Madigan et al., 2019; McManis \& Gunnewig, 2012; van der Kooy-Hofland et al., 2012).

These controversial findings might have occurred because the purpose of using digital devices was not distinguished in these studies (Kotrla Topić et al., 2020). In general, when screen time is used for learning purposes, confounding factors, such as online instruction and other learning activities, may be involved (Neumann, 2018). These confounding factors may dilute the possible negative influence of screen time. In addition, children spend an amount of time using electronic devices for entertainment purposes, for example watching videos and playing games, which involves few learning-related confounding factors (Fu et al., 2017; Kabali et al., 2015). Focusing on screen time for entertainment purposes could aid us to explore the broad effect of screen time on children's development.

A recent study of screen time for entertainment purposes (Kotrla Topić et al., 2020) reported that it correlated negatively with letter recognition in English-speaking preschool students. Yet, it is not clear whether screen time for entertainment 
purposes influences the role of sensorimotor experiences in conceptual processing. Due to the outbreak of COVID-19, public activities are discouraged and social distancing has led to children spending more time using digital devices for entertainment (Lau \& Lee, 2020; Wang et al., 2019). Although the current study was not conducted during the pandemic period, the results can still help us to gain a deeper insight into the BOI effect. As well, they can benefit diverse stakeholders, including parents, educators, and policymakers, by providing advice about managing children's entertainment in this unprecedented situation.

Screen time is a major reason for increasing sedentary behavior indoors and decreasing physical activities outdoors (Hingle \& Kunkel, 2012). Increased screen time can reduce opportunities for bodily interactions in the real world (Courage \& Setliff, 2010; Hingle \& Kunkel, 2012). Although children can acquire features of objects through using electronic devices, the complexity of the objects' properties is hardly equivalent to those in the real world. Specifically, objects are conveyed on digital screens via pre-made two-dimensional images, whereas they are three- or more- dimensional in the real world (Herodotou, 2018). Two-dimensional images can lead to a lack of some complex features of three-dimensional objects, in particular the features regarding the spatial aspect (Schilhab et al., 2018).

Moreover, screen time is related to narrower sensory input. During screen time, sensory input is typically dominated by visual and auditory systems, whereas other sensorimotor modalities, such as olfaction and gustation, may be neglected. As a result, fewer sensorimotor-related semantic nodes can be generated to integrate with linguistic units (Barsalou, 2008). Considering that the BOI effect is assumed to be enforced by richer semantic nodes with accumulated sensorimotor experiences (Louwerse, 2018; Siakaluk et al., 2008a, 2008b), it was assumed that higher screen time would be associated with smaller BOI effects.

On the other hand, the age effect has seldom been examined in research on screen time with children (e.g., Madigan et al., 2019; Neumann, 2018; Shamir \& Korat, 2007). Thus, the current study also examined whether there was an age difference in the role of screen time in the BOI effect. As described above, it was expected that the connection between the sensorimotor representation and the linguistic symbol might be stronger in the fourth graders (Barsalou, 2008; Loeffler et al., 2016; Wilson, 2002). It was predicted that this stronger connection would alleviate the impact of screen time on the association between BOI and word recognition. Thus, it was anticipated that the moderating effect of screen time on the BOI effect would be smaller in the fourth graders than in the second graders.

Moreover, to control their possible influences on the effects of interest, control variables including working memory, Chinese character reading, morphological awareness, and parents' ages and educational levels were taken into account in this study. Specifically, working memory, as a basic cognitive ability and one important component of executive functions (Carlson et al., 2002), may confound children's performances in the lexical decision task. As well, screen time for entertainment purposes may have an impact upon children's literacy abilities (McManis \& Gunnewig, 2012; van der Kooy-Hofland et al., 2012), which were correlated intimately to performance in the lexical decision task. As the current study was concerned with the possible influence of screen time on the association between sensorimotor 
experiences and word recognition, two literacy skills, Chinese character reading and morphological awareness, were included as covariates. On the other side, the two variables of family characteristics, parents' ages and educational levels (Li \& Rao, 2000; McBride-Chang et al., 2012), were controlled because they may have been associated with the parents' attitudes toward playing with digital tools. Accordingly, this may have been linked to difficulties with children's access to digital devices (Tandon et al., 2012), which could influence screen time.

\section{Present study}

In sum, to investigate the BOI effect, and the role of screen time on it, second- and fourth-grade Chinese children were recruited. The participants were asked to complete a lexical decision task for the BOI effect, and then they were asked to rate BOIs for the experimental words that were used in the lexical decision task. The participants' daily screen times for entertainment purposes were reported by their parents. In addition to working memory, the potential influences on reading of several factors were controlled. These were Chinese character reading and morphological awareness, age, gender, and nonverbal intelligence (Chiu \& McBride-Chang, 2006; McBride-Chang \& Chen, 2003). The present study had three research questions: (1) whether there would be a positive relationship between the BOI rating and word recognition (i.e., the BOI effect) in Chinese children; (2) whether the screen time would moderate this BOI effect; and (3) whether there would be an age (i.e., grade) difference in the BOI effect and the moderation of screen time on this effect.

\section{Method}

\section{Participants}

In total, parental permission to participate in the experiment was obtained from 140 (69 girls) second-grade students and 145 (64 girls) fourth-grade students. The children were recruited from a middle socioeconomic status public school in Zhejiang province, Mainland China. The mean ages were 7 years and 9 months ( $S D=4.44$ months) and 9 years and 9 months ( $S D=4.32$ months) for the second and fourth graders, respectively. Written informed parental consent forms were obtained for the participants. The participants were native speakers of Chinese (i.e., Putonghua) and had no physical or mental conditions, according to their teachers and parents.

\section{Procedure}

The participants were invited to complete a lexical decision task for the BOI effect at first. Then, they accomplished a series of tasks for nonverbal intelligence, working memory, Chinese character reading, and morphological 
awareness, which were conducted in a counterbalanced order. Finally, they were asked to complete a rating task for the BOIs of the experimental words in the lexical decision task.

\section{Measures}

\section{Lexical decision task}

A lexical decision task was adopted from previous studies (Siakaluk et al., 2008a, 2008b; Wellsby et al., 2011) and utilized to investigate the BOI effect in Chinese. The task consisted of 60 words and 60 nonwords in Chinese. In total, $24,15,8,9$, and 4 words were selected from Chinese textbooks for Grades 2 to 6 respectively, published by the People's Education Press. Each word represented a concept indicating an object, such as 剪刀/jian3 dao1/(scissors) and 蜡 烛/la4 zhu2/ (candle). On the other side, 23, 17, 14, 1, and 5 nonwords (nonsense words) were developed by randomly combining two characters from Chinese textbooks for Grades 2 to 6, respectively. For example, two characters 心/ xin1/ (heart) and 鸭/ya1/(duck) were used to make a nonword 心鸭.

The average complexities (i.e., the sum of strokes of two characters of each word) of the experimental words and the nonwords were 15.33 (ranging from 6 to 27) and 14.78 (ranging from 6 to 25), respectively. The character frequencies of words (Mean $=653$ per million words, ranging from 18 to 3273) and nonwords (Mean $=736$ per million words, ranging from 58 to 2906) were calculated by averaging the frequencies of two component characters ( $\mathrm{Da}, 2004)$. The words and nonwords were matched for the grade level of the item (i.e., the grade level of the corresponding textbook $\left(F(1,119)=0.19, p=0.66, \eta^{2}=0.002\right)$, the complexity $\left(F(1,119)=0.44, p=0.52, \eta^{2}=0.004\right)$, and the character frequency $\left(F(1,119)=0.47, p=0.50, \eta^{2}=0.004\right)$. Furthermore, to ensure there were no characters unfamiliar to the participants and that the nonwords did not make sense, the words and nonwords were checked by two of the participants' Chinese teachers. The average word frequency of these experimental words was 0.04, ranging from 0.005 to $0.16(\mathrm{Da}, 2004)$. To reduce possible influences on the BOI effect and its relationship with screen time, the item's grade level, complexity, and frequency were taken into account in the data analysis.

In the task, each trial started with the presentation of a fixation cross at the centre of the screen for $400 \mathrm{~ms}$, and then a word or a nonword appeared at the centre of the screen for $2000 \mathrm{~ms}$. After that, the participants were asked to judge, as quickly and accurately as possible, whether the word made sense. Half of the participants used the "F" key on the keyboard to provide a "yes" response and the "J" key to provide a "no" response; for the other half, the response keys were reversed. The next trial began after a $1000 \mathrm{~ms}$ blank screen. The trials were presented in a random order, and the task took approximately $10 \mathrm{~min}$ to complete. 


\section{Nonverbal intelligence}

The children's nonverbal intelligence was measured by Raven's Standard Progressive Matrices, i.e., sets A, B, and C (Raven, 1996). There were 36 items, and the maximum score was 36 . For each test item, the children were asked to identify the missing element from six or eight options, according to a pattern. The Cronbach's alphas were 0.85 and 0.90 for the second and fourth graders, respectively.

\section{Working memory}

A backward digit recall task (Alloway \& Alloway, 2010) was used to measure working memory. That is, the children were asked to recall 14 strings of Arabic digits (e.g., 6-7-3) in the reverse order (e.g., 3-7-6) after listening to each string. The digit strings ranged from two to eight digits long and were arranged in order of increasing length. The accuracy of each sequence was recorded, and the maximum score was 14. The Cronbach's alphas were 0.69 and 0.77 for the second and fourth graders, respectively.

\section{Chinese character reading}

A test for Chinese character reading (Liu \& McBride-Chang, 2010) was adopted to examine the children's reading abilities at the word level. The participants were required to read 100 characters aloud, one by one. The test was stopped if a child failed to recognize 15 consecutive characters. Each correct character was given one point, and the maximum score for Chinese character reading was 100 . The Cronbach's alphas were 0.94 and 0.81 for the second and fourth graders respectively.

\section{Morphological awareness}

Morphological awareness was examined using a compounding production task (Liu et al., 2017). There was a total of 31 items. For each item, a scenario was presented and the participants were asked to create a novel word to represent it properly. For example, one example scenario in this task was “我们把用草制成的伞叫做什么 呢? (What should we call an umbrella that is made of grass?)" The answer for this item was草伞 (grass umbrella). The answers were rated on a five-point scale, ranging from 0 to 4 . The maximum score was 124 . The Cronbach's alphas were 0.89 and 0.86 for the second and fourth graders respectively.

\section{BOI rating}

After completing the aforementioned measures, the participants were asked to complete a rating task for the 60 words in the lexical decision task. The results of this test were utilized as the BOI ratings for the corresponding words. The BOI rating procedure was the same as for the lexical decision task, except that instead of judging whether the words made sense, the children were asked to rate on a 1-7 scale how easily they could interact physically with each word's referent. A rating of 1 
was extremely easy (e.g., pencil), and 7 was extremely difficult (e.g., coal). Before the rating, each participant was asked to give two examples of words, one with a relatively high BOI value and one with a low value. The answers were checked by a trained experimenter to ensure the participant understood the instructions about rating. The experiment took approximately five minutes to complete. The Cronbach's alphas were 0.95 for both the second and the fourth graders.

\section{Parents' information and screen time}

Once informed consent was gained from them, the participating parents were asked to report demographic information about their children (i.e., the birthday, any physical or mental problems) and themselves (i.e., age and education level of the father and mother). The parents' education levels were measured on a 7-point scale: $1=$ third grade or below, $2=$ fourth grade to sixth grade, $3=$ middle school, $4=$ high school, $5=$ college school, $6=$ university, $7=$ postgraduate. As well, the parents were asked to answer a question about the time (in minutes) their children spent using digital devices for entertainment purposes (e.g., playing games, searching the Internet, watching videos, or visiting social networks) on a typical day (Kotrla Topić et al., 2020; Neumann, 2018).

\section{Results}

\section{Preliminary analyses}

Three second graders (one girl) and one fourth-grade boy did not complete the lexical decision task due to a program malfunction. Another five second graders (three girls) and four fourth graders (one girl) were excluded because their overall accuracy rates (including non-words) were less than $60 \%$. As the aim of the current study was the BOI effect, only the real words in the lexical decision task were taken into account in the analysis. Response latencies that were three standard deviations above or below a participant's condition mean for correct responses were excluded $(3.18 \%)$.

Descriptive statistics for lexical decision performance, nonverbal intelligence, working memory, Chinese character reading, morphological awareness, and the parent-reported daily screen time for the participants in both grades and the results of the MANOVA analyses are summarized in Table 1.

Inspection of skew and kurtosis statistics suggested that the data were normally distributed, however, nonverbal intelligence, morphological awareness, and screen time of the fourth graders appeared to be heavy-tailed. The results of the MANOVA analyses showed that, for the lexical decision task, the children in Grade 4 showed higher accuracy (mean difference $=0.05$ ) and fewer response times (mean difference $=-264.70 \mathrm{~ms}$ ) than those in Grade 2. The fourth graders had significantly higher scores on the Chinese character reading (mean difference $=17.15$ ) and morphological awareness (mean difference $=18.15$ ) tasks than the second graders, indicating the more developed literacy skills of the former. In addition, the fourth 


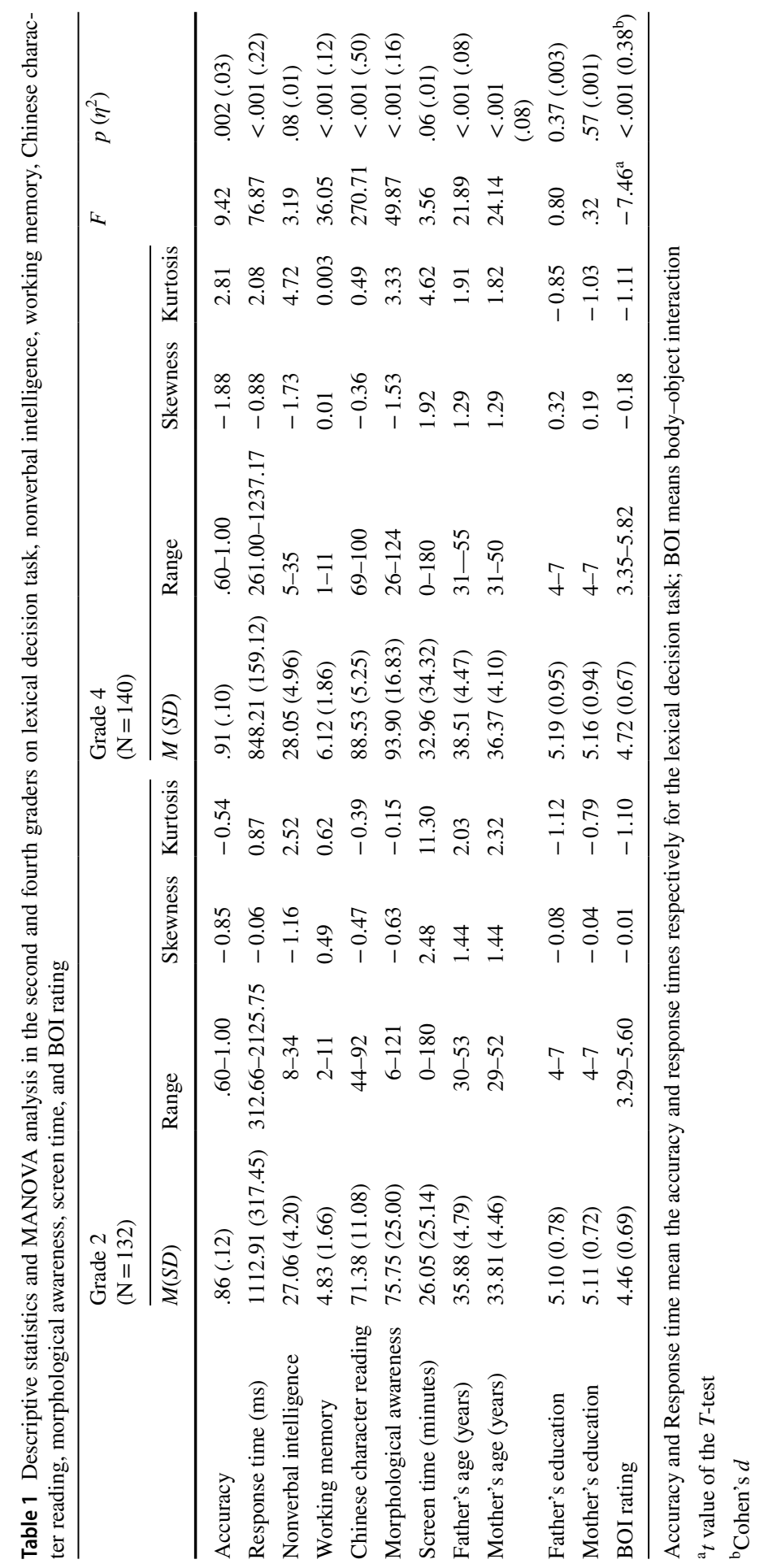


graders showed better performance on the working memory task (mean difference $=1.28$ ), but their nonverbal intelligence (mean difference $=0.99$ ) and the screen time (mean difference $=6.91$ ) were similar to those of the second graders. For the parent-related variables, the fourth graders' fathers' (mean difference $=2.63$ ) and mothers' (mean difference $=2.55$ ) ages were higher than those of the second graders' parents.

To acquire an overall view of the relationships between the aforementioned measures, correlation analyses were conducted by grade, with partial control of age and nonverbal intelligence. The results are summarized in Tables 2 and 3. For the second graders, the Chinese character reading score was positively correlated with the accuracy of the lexical decision task $(p=0.03)$ and the working memory performance $(p=0.04)$. Father's age was negatively correlated with the Chinse character reading score $(p=0.002)$ but positively correlated with mother's age $(p<0.001)$. Father's education level was positively correlated working memory performance $(p=0.01)$ and Chinese character reading $(p=0.02)$, but it was negatively related to father's age $(p=0.01)$ and mother's age $(p=0.04)$. The mother's education level was positively correlated with the accuracy rate of the lexical decision task $(p=0.01)$, the score for Chinese character reading $(p=0.02)$, and the father's education level $(p<0.001)$.

For the children in Grade 4, there was a significant positive correlation between the accuracy and response time on the lexical decision task $(p<0.001)$, illustrating that a speed-accuracy trade-off was operating (Heitz, 2014). In addition, Chinese character reading performance significantly correlated with the response time on the lexical decision task $(p=0.02)$, working memory $(p<0.001)$, and morphological awareness $(p<0.001)$. Father's age was positively correlated with mother's age. As well, the father's education level was positively correlated with the mother's education level $(p<0.001)$.

Regarding the stimuli in the lexical decision task, the results of the BOI rating of the 60 experimental words between these two grades were also compared by $T$-test (see Table 1). Overall, the BOIs of these 60 words were rated higher by the children in Grade 4 than by those in Grade 2 (mean difference=0.26). A correlation analysis showed that the correlation of the BOI ratings between these two grades was strong $(r=0.92, p<0.001)$.

\section{LMM analysis}

Two LMMs (i.e., Models 1 and 2) were conducted for the three research questions: (1) whether the BOI effect in word recognition was significant in Chinese children;

(2) whether the BOI effect was influenced by screen time; and (3) whether there were differences in the BOI effect and its relationship with the screen time for the participants in different grades (i.e., Grades 2 and 4). The LMM analysis was conducted by using the lmer program of the lme4 package in R 4.0.3 (R Core Team, 2020), and the significance of the fixed effect was assessed by using the lmerTest package.

The accuracy and response time for the experimental words in the lexical decision task were the dependent variables for Models 1 and 2, respectively. It should be 


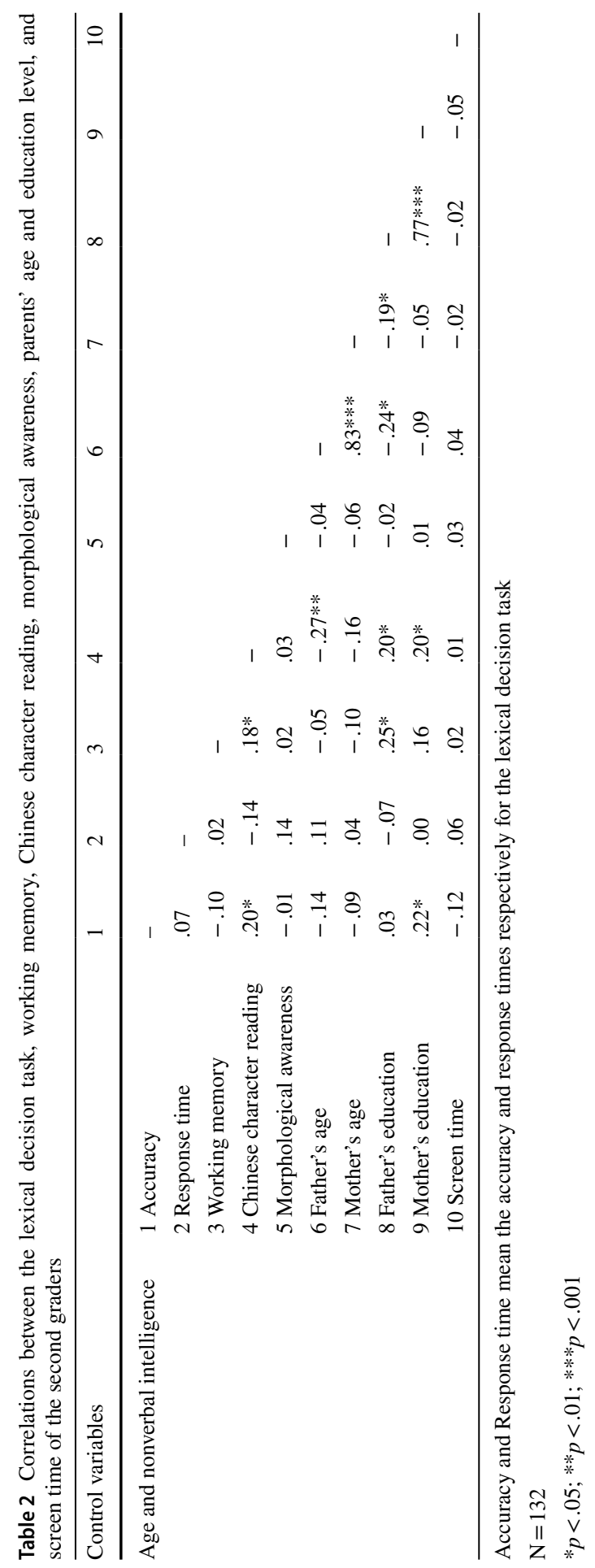




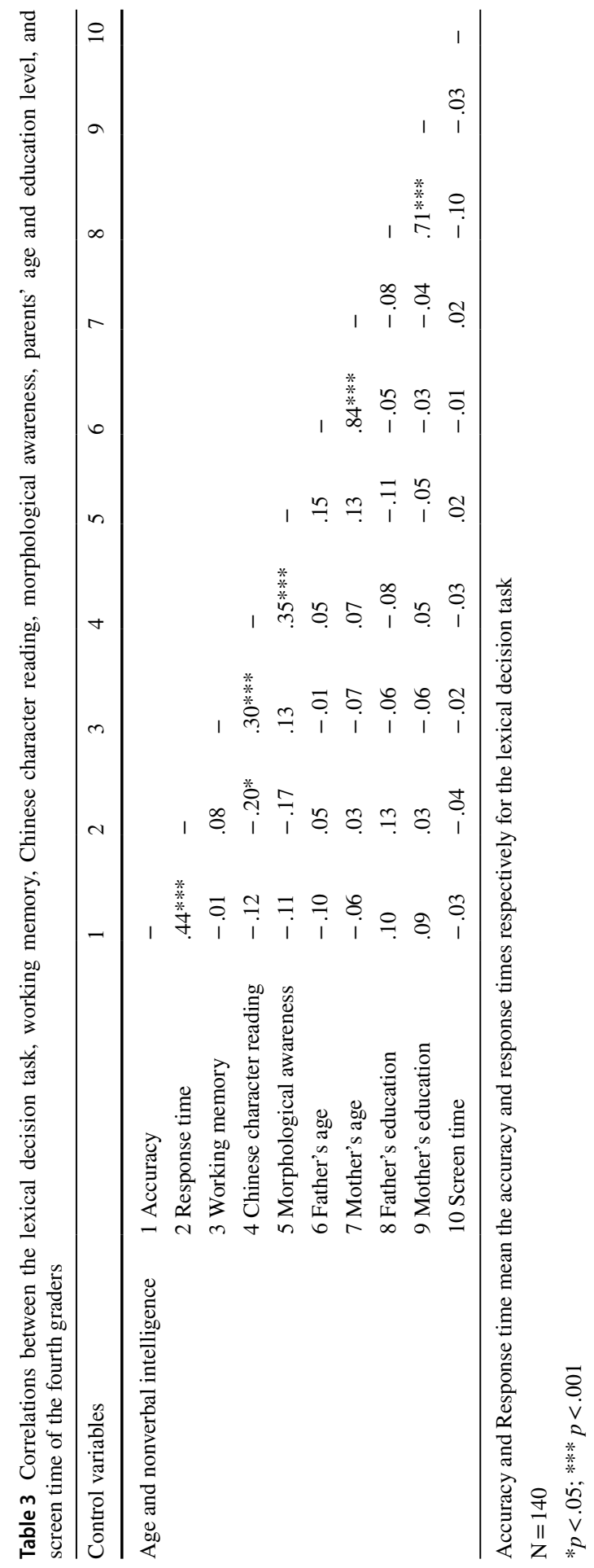


noted that the average accuracy and response time of each participant was adopted in the preliminary analyses. However, the accuracy and response time of each trial was utilized in the LMM analyses. The fixed and random factors were identical in Models 1 and 2. Specifically, the fixed variables in these two models were the BOI rating, grade, screen time, and the interactions between the three fixed variables. For each grade, the BOI rating of each word was the average of all participants in this grade. In addition, the fixed variables also included covariates about the participants (i.e., age, gender, nonverbal intelligence, working memory, Chinese character reading, morphological awareness, and parents' ages and education levels) and the experimental words (i.e., the grade, complexity, and frequency of the item).

The random effects included individual differences in the participants, as well as in the experimental words. In addition, to overcome the problem of collinearity, the continuous factors (i.e., the response time, BOI rating, screen time, age, nonverbal intelligence, parents' ages, and the complexity and frequency of the experiment words) were centred by $z$-score transformation of raw scores. As well, for grade and gender, the contrasts between the conditions were utilized in the models. Grade 2 and boys were set as references for the contrasts of grade and gender, respectively. The results for Models 1 and 2 are summarized in Table 4.

Models 1 and 2 showed significant facilitating effects of the BOI rating on both accuracy and response speed levels, after controlling the variables relating to the participants (i.e., age, gender, nonverbal intelligence, working memory, Chinese character reading, morphological awareness, and parents' ages and education levels), as well as those relating to the experimental words (i.e., the grade, complexity, and the frequency of the item). That is, in the lexical decision task, the accuracy rate and the response speed improved with increasing BOI ratings. The effects of grade and screen time were non-significant in both models $(p s>0.05)$. When reading-related abilities and the properties of the experimental words were controlled, the children in Grades 2 and 4 had similar performances on the lexical decision task. As well, the screen time did not influence overall performance on the lexical decision task.

The two-way interactions between the BOI rating, screen time, and grade, as well as the three-way interaction among them, were non-significant in Model 1 $(p s>0.05)$. Similarly, the interaction between the BOI rating and grade and the interaction between grade and screen time were not significant in Model 2 ( $p s>0.05)$. Importantly, Model 2 displayed a significant interaction between the BOI rating and the screen time and a significant three-way interaction among the BOI rating, screen time, and grade. The interaction between the BOI rating and screen time showed that the facilitating BOI effect on word recognition was reduced by the increase in screen time. The three-way interaction illustrated that the impact of the screen time on the BOI effect was greater in the second graders than in the fourth graders. The results for Model 2 are illustrated in Fig. 1, which was developed by using the ggplot package in R 4.0.3 (R Core Team, 2020). The three lines in Fig. 1 represent the variance (i.e., low, medium, and high levels) of the screen time in the current sample.

Of the control variables, only the effect of frequency was significant in both models. The experimental words with higher item frequency elicited higher accuracy rates and faster response speeds in the lexical decision task. The effect of gender was significant in the accuracy analysis; the girls had higher accuracy than the boys. The 


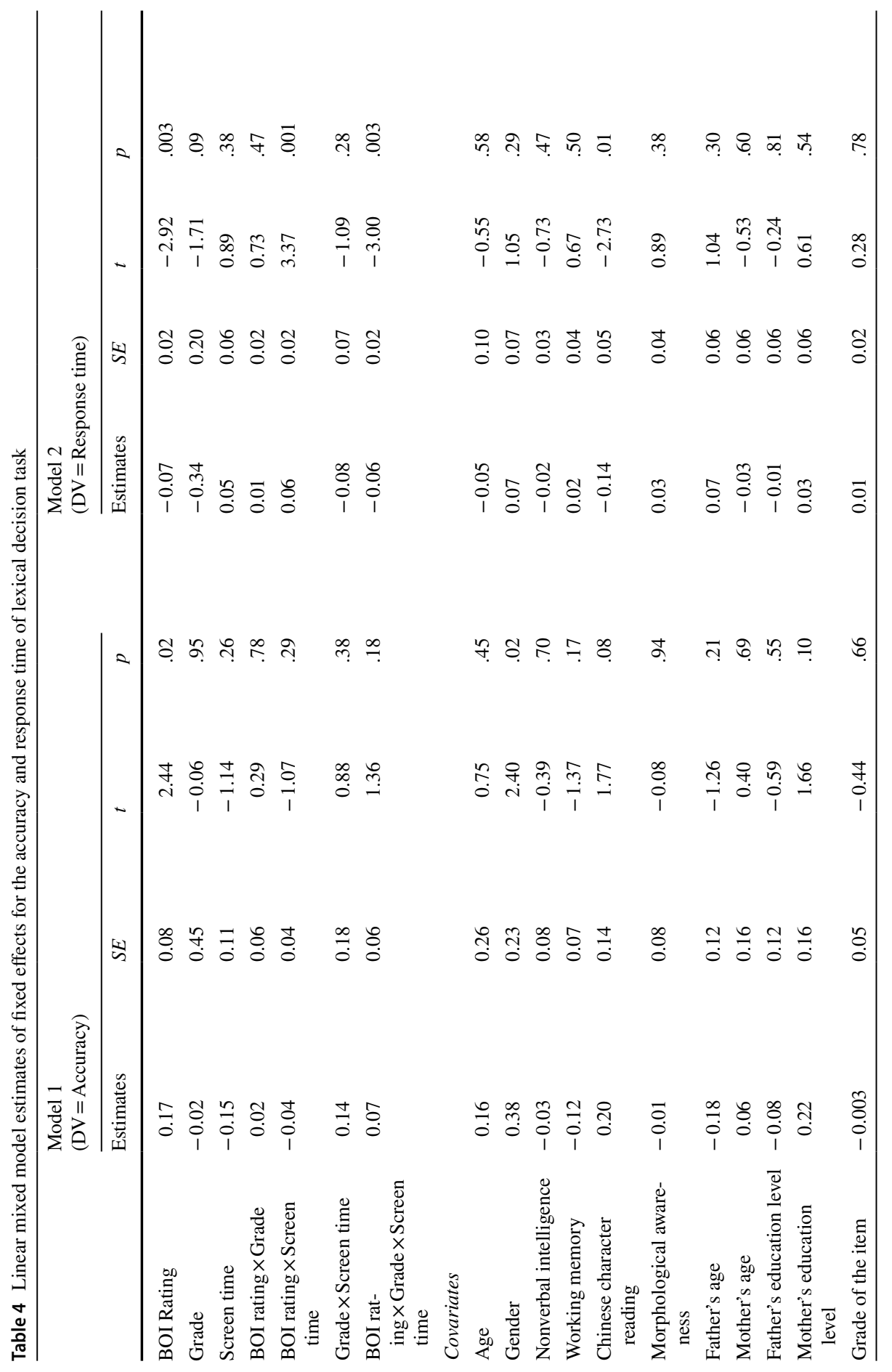




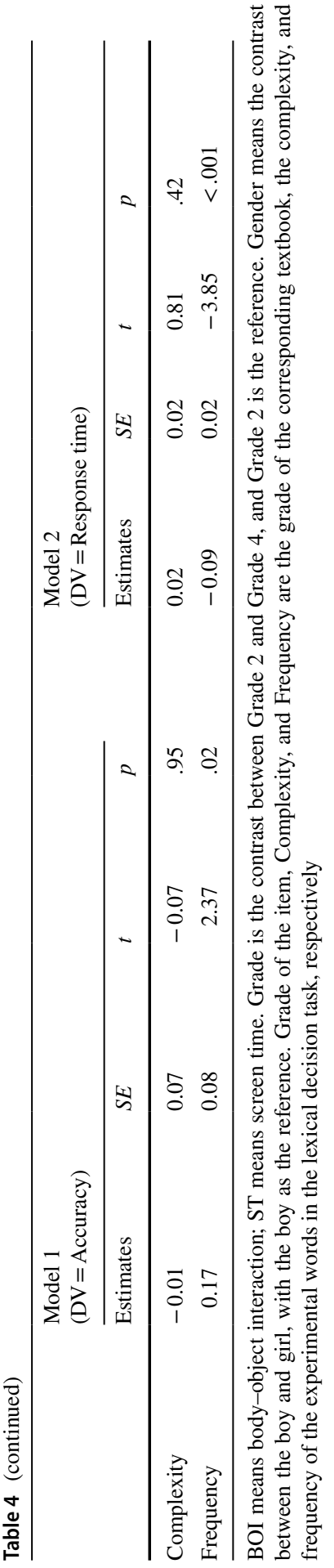




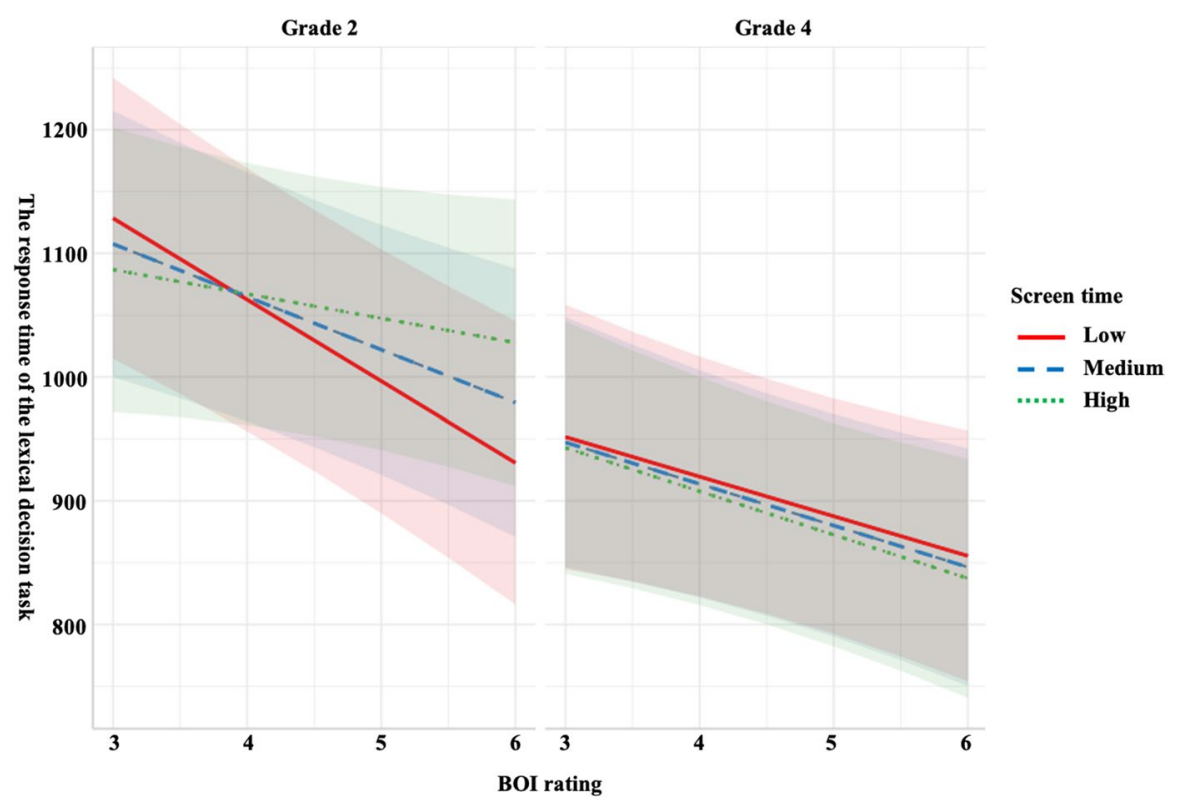

Fig. 1 The Role of Screen Time in the Association between Body-Object Interaction (BOI) Rating and Word Recognition at the Response Time Level in Chinese Children. Note The flatter line indicates a smaller BOI effect. The figure shows that the slope of the line flattens with the increase of screen time

latency analysis showed a significant effect of Chinese character reading. The children with higher Chinese character reading scores showed higher response speeds in the lexical decision task.

\section{Discussion}

The current study investigated the relationship between BOI ratings and word recognition (i.e., the BOI effect), and the moderating role of screen time in the BOI effect in Chinese-speaking Grades 2 and 4 students. The findings illustrated that: (1) the BOI effect was significant for aspects of the response accuracy and speed in Chinese children; (2) the BOI effects did not differ with grade; (3) at the response time level, the BOI effect was reduced with increasing screen time; and (4) the impact of screen time on the BOI effect at the response time level was smaller in the fourth graders than in the second graders.

\section{BOI effect on word recognition in Chinese children}

The current study extended previous research with English-speaking children (Inkster et al., 2016; Wellsby \& Pexman, 2014) by illustrating that, with the child-rated 
BOI, the facilitating BOI effect in word recognition occurs in Chinese children both below and above eight years of age. These findings were inconsistent with those of Wellsby and Pexman (2014), in which the facilitating BOI effect was not observed in children below the age of eight. This difference might have occurred because the BOI of words was rated by the participants in the current study, but was rated by adults in the Wellsby and Pexman (2014) study. Nevertheless, consistent with the current result, Inkster et al. (2016) reported a significant BOI effect in children below eight years old, although this was with parents reporting BOI ratings on behalf of the participants.

On the other hand, different from the previous work with alphabetic-language speaking children (i.e., Inkster et al., 2016; Wellsby \& Pexman, 2014), the current findings showed that, in addition to the latency-level BOI effect, the facilitating BOI effect was also evident for the accuracy level in Chinese. One possible interpretation for this significant BOI effect at the accuracy level is that the current study utilized the BOI ratings from the participants, which enabled the effect of the BOI on word recognition to be examined more directly. Similar findings have been revealed in studies with English-speaking adults (Siakaluk et al., 2008a, 2008b; Tousignant \& Pexman, 2012). With BOI ratings from a separate group of adults in the same age group as the participants, these studies revealed significant BOI effects on word recognition at the response accuracy and speed levels. Together, these findings highlight the role of the individual in rating the BOIs of words. The BOI effect reflects the contribution of an individual's experiences concerning bodily interactions of objects to the conceptual processing. Different daily routines could lead to distinctive BOI ratings on a certain concept. Thus, the ratings from others, especially from those in other age groups, can interfere with the BOI effect.

The facilitating BOI effect with children demonstrated that the sensorimotor information is beneficial for word recognition, which supports the role of BOIs in concept acquisition (Bennett et al., 2011; Glenberg \& Gallese, 2012; Tillotson et al., 2008). As described above, more bodily interactions between readers and corresponding objects of concepts can result in more sensorimotor representations for readers to integrate with related linguistic symbols (Glenberg et al., 2007; Sadoski $\&$ Paivio, 2004). Thus, compared to low BOI words, high BOI words are assumed to arise in more nodes relating to their conceptual meanings. These nodes can settle more efficiently to the activation of stable patterns of semantic representations (Plaut \& Shallice, 1993; Wellsby et al., 2011). As a consequence, lexical retrieval can be facilitated.

As well, the facilitating BOI effect at the accuracy and latency levels supports a critical role of sensorimotor experiences in conceptual processing in the Chinese language. As mentioned above, the concrete objects and events, which have close correlations with sensorimotor experiences, play crucial roles in expressing concepts in the Chinese language (Yu, 2009). Considering that sensorimotor features can contribute to the construction of conceptual meaning, it is possible that these sensorimotor representations can benefit Chinese children's word recognition, not only at the response speed level but also at the accuracy level (Li et al., 2007; Wang et al., 2005). 
On the other hand, in general, the BOI ratings of the words in the current study were higher for the fourth graders than for the second graders. The higher BOI ratings of the fourth graders imply more accumulated sensorimotor experiences of corresponding concepts (Siakaluk et al., 2008a, 2008b). Inconsistent with our assumption, the findings demonstrated that the facilitating BOI effect did not increase with age. Although the fourth graders had higher BOI ratings than the second graders overall, the range of the BOI ratings in the current sample was relatively high and narrow (Grade 2: ranging from 3.29 to 5.60; Grade 4: ranging from 3.35 to 5.82). It is possible that the objects used in the current study were relatively familiar to the children in these two grades. The children at the beginning stage of literacy acquisition (e.g., Grade 2) may have gained enough sensorimotor features, which could be used to construct connections with linguistic symbols (Kontra et al., 2012; Smith \& Gasser, 2005). Thus, more bodily interactions with the objects at a later age (e.g., Grade 4) maybe not enough to elicit any significant change in the facilitating BOI effect. It is worth noting that, as the range of the BOI rating is limited, it is not clear whether the age difference in the BOI effect would emerge in processing concepts with extremely low or high BOI ratings.

Alternatively, the overall performance on the lexical decision task may also have influenced the results. Specifically, the correlation analyses showed that the average accuracy correlated positively with the average speed in the fourth graders, but not in the second graders. That is, the speed-accuracy trade-off operation was only observed in the children in Grade 4. The Grade 4 children's task performances were reduced due to a slower processing speed in favor of higher accuracy (Heitz, 2014). To control the impacts of variables regarding the participants and the stimuli, the current study utilized the LMM analyses, making it difficult to consider the influence of the speed-accuracy trade-off operation simultaneously (Luke, 2017). However, it is possible that the reduced performance of the fourth graders, in particular at the latency level, could have hindered the older children from taking advantage of more accumulated sensorimotor experiences. Of note, these possible interpretations should be explored further in future studies.

\section{BOI effect and screen time in children}

The significant interaction between the BOI rating and screen time was only observed in the latency analysis. The results suggest that the increased screen time could reduce the facilitating BOI effect in word recognition at the response speed level, but not at the accuracy level. These distinct roles of screen time in the BOI effect at latency and accuracy levels may be related to the nature of the BOI effect. As described before, concepts with high BOIs have richer semantic representations, leading to stronger feedback onorthographic and phonological representations. Accordingly, the settling in these representations can be more efficient, resulting in faster response latencies in lexical processing tasks. In contrast, more effortful and extensive lexical and semantic processing is required for concepts with less sensorimotor-related semantic representations (Pexman et al., 2007). Thus, it is possible that the BOI effect at the latency level would be more sensitive to potential 
influences than the effect at the accuracy level. Consistently, as mentioned above, Siakaluk et al., (2008a, 2008b) reported that only the latency analysis revealed that a larger BOI effect could emerge in the lexical processing tasks that require more semantic representations, although the BOI effect was significant in both the accuracy and latency analyses. Future studies could examine this possible interpretation further.

The current results suggest a possibility that the increased screen time could reduce the facilitating effect of sensorimotor experiences on lexical processing efficiency. A possible interpretation is that screen time may impair the constitution of richer semantic representations regarding sensorimotor experiences. Specifically, the increased time for using digital tools, for entertainment at least, relatively reduces the time of bodily interactions with physical objects (Hnatiuk et al., 2014; Pate et al., 2008). Although activities with digital tools can provide sensorimotor features of objects, the quality of these features is still different from those gained from physical interactions in the real world. Generally, digital tools display two-dimensional objects, which may lead to a lack of some sensorimotor features of three- or moredimensional objects (Barr, 2013). For example, children may have difficulty gaining the shape of a rose through a two-dimensional image only. On the other hand, interactions with objects in screen time and these in the real world differ in modalities. Digital tools focus on the visual and auditory modalities, whereas more modalities are involved in physical interactions. For instance, an image of a rose on a digital tool cannot convey its smell, which is a critical feature of the rose.

In addition, these two-dimensional images of objects that are presented on the screen are pre-made. Children may have fewer chances to manipulate these objects actively (Sweetser et al., 2012). On the contrary, with active manipulations in physical interactions, they could allocate more attention to their unfamiliar features to enrich sensorimotor representations of objects. Moreover, in the actual environment, the motor system can be involved in the interactions with objects through different body parts. For example, children can play basketball and football using their hands and feet to acquire embodied information via the motor system. In turn, this different information from the motor system can be reactivated during lexical retrieval to facilitate word recognition (Dijkstra et al., 2004; Kiefer \& Trumpp, 2012). However, the actions that are related to the screen generally only involve hands. Furthermore, different from various hand actions in the actual environment (e.g., grasp, pull, and push), the actions that relate to digital tools focus on tapping with fingers.

As well, the experiences about the haptic system, e.g., touching objects, may lead to difference in the acquisition of sensorimotor features (Minogue \& Jones, 2006; Schönborn et al., 2011). The haptic experiences can contribute to specific representations in the haptic modality, which cannot be replaced by representations in other modalities (Barsalou et al., 2003; Skulmowski et al., 2016). In the case of physical interactions, through the haptic modality, children can acquire properties of objects such as texture, shape, length, size, and weight. These properties are hard to gain from viewing screens. Even in the case of using digital devices like tablets and smartphones, the experiences in the haptic system are related to interactions between hands/fingers and screens, but not objects. More importantly, the experiences in the haptic system can provide information about trajectory and amplitude 
corresponding to objects (Hennion et al., 2005). The trajectory and amplitude can lead to force feedback, which is beneficial for children to perceive, identify, and memorize perceptual features of objects (Sigrist et al., 2013). Taken together, such differences might lead to relatively less acquisition of complex sensorimotor information via using digital tools (James \& Engelhardt, 2012; Kiefer et al., 2015), which can further weaken the effect of BOI on word recognition.

Moreover, an age difference in the relationship between the BOI effect and screen time was revealed in the response time analysis. The impact of screen time on the BOI effect was larger for the children in Grade 2 than for those in Grade 4. Consider that reading ability and linguistic-related semantic knowledge were controlled in the analysis, this age difference in the BOI effect should not be a result of more developed reading abilities (Louwerse, 2018). The current results suggest that the second graders had a similar BOI effect to that of the fourth graders. However, the second graders' connections between linguistic knowledge and sensorimotor experiences may have been fragile relative to the fourth graders', as younger children generally have more difficulties in mapping sensorimotor nodes onto verbal nodes (Paivio, 2010; Wilson, 2002). Thus, it is possible that the BOI effect in the second graders would be moderated more heavily by screen time than it would in the fourth graders. Together, the results suggest that, although the extra sensorimotor experiences of the children in Grade 4 did not elicit larger BOI effects in general, it might be helpful to establish stronger connections between sensorimotor features and linguistic nodes which could, in turn, reduce the influence of the increasing screen time on the BOI effect on word recognition.

\section{Limitations and future studies}

The current study revealed a negative correlation between the BOI effect and screen time. To explore the mechanism underlying this correlation further, more possible influential factors should be taken into account in future studies. First, different devices (e.g., computers and smartphones) may provide different opportunities or approaches (e.g., active or passive) for children to interact with objects (Sweetser et al., 2012). Accordingly, the role of screen time in the BOI effect might be varied. Second, to exclude the influence of literacy knowledge, the current study only focused on screen time for entertainment purposes. However, screen time for learning purposes has been shown to account for a substantial part of children's use of digital devices (Kotrla Topić et al., 2020; Sousa \& Rocha, 2019). Investigations of screen time for learning purposes could deepen our understanding of the mechanisms of the role of screen time for different purposes in the BOI effect with children.

Third, no age differences were revealed in the BOI effect in the current study. As mentioned above, this result might be related to the relatively narrow range of the BOI ratings or the speed-accuracy trade-off operation of the older children in the current sample. With consideration of the speed-accuracy trade-off operation, longitudinal studies involving children in different grades, as well as words with larger variances in terms of the BOI rating, can be conducted in the future. As well, although the item grade levels were controlled in the current study, future studies could select stimuli that are matched for difficulty for different grades to investigate whether this would lead to 
any impacts on the BOI effect and its relationship with age. Last but not least, although some covariates have been considered in the current study, to achieve a comprehensive understanding of the relationship between the BOI effect and screen time, future studies could explore more the roles of other latent variables, such as learning motivation and attention (Broussard \& Garrison, 2004; Lissak, 2018).

\section{Theoretical and educational implications}

Consistent with previous studies in alphabetic languages (Inkster et al., 2016; Wellsby \& Pexman, 2014), the current study illustrated the facilitating BOI effect in Chinese children. The findings suggest the involvement of sensorimotor information in constructing and retrieving concepts in the Chinese language. That is, sensorimotor experiences are vital in developing conceptual knowledge; in turn, retrieval of conceptual meaning involves the reactivation of sensorimotor experiences (Louwerse, 2018; Louwerse \& Jeuniaux, 2010). On the other hand, the current study has extended previous findings by illustrating that the facilitating BOI effect was weakened in children with longer screen time. This finding supports that the involvement of digital tools in daily life, in particular for young children (e.g., second graders), might influence bodily interactions with objects and environments. As a result, the construction of the sensorimotor representation and its role in concept processing can be impacted (Dubé \& McEwen, 2015; Williams et al., 2009).

Practically, the current findings suggest that more physical interactions between children's bodies and objects should be involved in concept acquisition. Such interactions can form a basis for developing children's knowledge of concepts, so they should be introduced at the beginning stage of literacy acquisition. On the other hand, the study found that screen time weakened the effect of BOI on word recognition, demonstrating that increasing screen time may lead to an insufficient acquisition of sensorimotor experiences. Thus, in addition to increasing physical interactions with objects, children's screen time should be controlled, especially for entertainment purposes, at least at the beginning and middle stages of concept acquisition.

Acknowledgements This study was partially supported by RGC Grant [Grant No. 18602520] of The Education University of Hong Kong in Hong Kong Special Administrative Region. We thank all the children, their parents and teachers, for their participation.

Authors' contributions Both authors contributed to the study conception and design. ZX and DL designed and conducted tasks, collected and analyzed data, and co-wrote the paper.

Funding This study was partially supported by an RGC Grant [Grant No. 18602520] from The Education University of Hong Kong in the Hong Kong Special Administrative Region.

Data availability The data that support the findings of this study are available from the corresponding author upon reasonable request.

Code availability Not applicable. 


\section{Declarations}

Conflict of interest We have no known conflict of interest to disclose.

Ethical approval The ethical considerations of the current study were approved by Human Research Ethics Committee at The Education University of Hong Kong.

Consent to participate Written informed parental consent was obtained for all participants.

Consent for publication Upon acceptance, we, ZX and DL, grant the Publisher an exclusive licence to publish the article.

\section{References}

Alloway, T. P., \& Alloway, R. G. (2010). Investigating the predictive roles of working memory and IQ in academic attainment. Journal of Experimental Child Psychology, 106(1), 202-209. https://doi. org/10.1016/j.jecp.2009.11.003

Antonucci, S. M., \& Alt, M. (2011). A lifespan perspective on semantic processing of concrete concepts: Does a sensory/motor model have the potential to bridge the gap? Cognitive, Affective, and Behavioral Neuroscience, 11(4), 551-572. https://doi.org/10.3758/s13415-011-0053-y

Barr, R. (2013). Memory constraints on infant learning from picture books, television, and touchscreens. Child Development Perspectives, 7(4), 205-210. https://doi.org/10.1111/cdep.12041

Barsalou, L. W. (2008). Grounded cognition. Annual Review of Psychology, 59, 617-645. https://doi. org/10.1146/annurev.psych.59.103006.093639

Barsalou, L. W., Simmons, W. K., Barbey, A. K., \& Wilson, C. D. (2003). Grounding conceptual knowledge in modality-specific systems. Trends in Cognitive Sciences, 7, 84-91. https://doi.org/ 10.1016/S1364-6613(02)00029-3

Bennett, S. D., Burnett, A. N., Siakaluk, P. D., \& Pexman, P. M. (2011). Imageability and body-object interaction ratings for 599 multisyllabic nouns. Behavior Research Methods, 43(4), 1100-1109. https://doi.org/10.3758/s13428-011-0117-5

Broussard, S. C., \& Garrison, M. B. (2004). The relationship between classroom motivation and academic achievement in elementary-school-aged children. Family and Consumer Sciences Research Journal, 33(2), 106-120. https://doi.org/10.1177/1077727X04269573

Carlisle, J. F. (2000). Awareness of the structure and meaning of morphologically complex words: Impact on reading. Reading and Writing, 12(3), 169-190. https://doi.org/10.1023/A:1008131926 604

Carlson, S. M., Moses, L. J., \& Breton, C. (2002). How specific is the relation between executive function and theory of mind? Contributions of inhibitory control and working memory. Infant and Child Development: An International Journal of Research and Practice, 11(2), 73-92. https://doi.org/10. 1002/icd.298

Chiu, M. M., \& McBride-Chang, C. (2006). Gender, context, and reading: A comparison of students in 43 countries. Scientific Studies of Reading, 10(4), 331-362. https://doi.org/10.1207/s1532799xs sr1004_1

Chung, F. H. K., \& Leung, M. T. (2008). Data analysis of Chinese characters in primary school corpora of Hong Kong and mainland China: Preliminary theoretical interpretations. Clinical Linguistics and Phonetics, 22(4-5), 379-389. https://doi.org/10.1080/02699200701776757

Courage, M. L., \& Setliff, A. E. (2010). When babies watch television: Attention-getting, attention-holding, and the implications for learning from video material. Developmental Review, 30(2), 220-238. https://doi.org/10.1016/j.dr.2010.03.003

Da, J. (2004). A corpus-based study of character and bigram frequencies in Chinese e-texts and its implications for Chinese language instruction. In P. Zhang, T. Xie, \& J. Xu (Eds.), The studies on the theory and methodology of the digitalized Chinese teaching to foreigners: Proceedings of the fourth international conference on new technologies in teaching and learning Chinese (pp. 501-511). Tsinghua University Press. 
Dias, P., Brito, R., Ribbens, W., Daniela, L., Rubene, Z., Dreier, M., Gemo, M., Gioia, R., \& Chaudron, S. (2016). The role of parents in the engagement of young children with digital technologies: Exploring tensions between rights of access and protection, from 'Gatekeepers' to 'Scaffolders.' Global Studies of Childhood, 6(4), 414-427. https://doi.org/10.1177/2043610616676024

Dijkstra, K., Yaxley, R. H., Madden, C. J., \& Zwaan, R. A. (2004). The role of age and perceptual symbols in language comprehension. Psychology and Aging, 19(2), 352-356. https://doi.org/10.1037/ 0882-7974.19.2.352

Dove, G. (2016). Three symbol ungrounding problems: Abstract concepts and the future of embodied cognition. Psychonomic Bulletin and Review, 23(4), 1109-1121. https://doi.org/10.3758/ s13423-015-0825-4

Dubé, A. K., \& McEwen, R. N. (2015). Do gestures matter? The implications of using touchscreen devices in mathematics instruction. Learning and Instruction, 40, 89-98. https://doi.org/10.1016/j. learninstruc.2015.09.002

Fu, K. W., Ho, F. K. W., Rao, N., Jiang, F., Li, S. L., Lee, T. M. C., Chan, S. H., Yung, A. W., Young, M. E., \& Ip, P. (2017). Parental restriction reduces the harmful effects of in-bedroom electronic devices. Archives of Disease in Childhood, 102(12), 1125-1131. https://doi.org/10.1136/archdischi ld-2017-312639

Gibbs, R. (1999). Taking metaphor out of our heads and putting it into the cultural world. In R. Gibbs \& G. Steen (Eds.), Metaphor in cognitive linguistics (pp. 145-166). John Benjamins.

Glenberg, A. M., Brown, M., \& Levin, J. R. (2007). Enhancing comprehension in small reading groups using a manipulation strategy. Contemporary Educational Psychology, 32(3), 389-399. https://doi. org/10.1016/j.cedpsych.2006.03.001

Glenberg, A. M., \& Gallese, V. (2012). Action-based language: A theory of language acquisition, comprehension, and production. Cortex, 48(7), 905-922. https://doi.org/10.1016/j.cortex.2011.04.010

Harm, M. W., \& Seidenberg, M. S. (2004). Computing the meanings of words in reading: Cooperative division of labor between visual and phonological processes. Psychological Review, 111(3), 662720. https://doi.org/10.1037/0033-295X.111.3.662

Heitz, R. P. (2014). The speed-accuracy tradeoff: History, physiology, methodology, and behavior. Frontiers in Neuroscience, 8, 150. https://doi.org/10.3389/fnins.2014.00150

Hennion, B., Gentaz, E., Gouagout, P., \& Bara, F. (2005). Telemaque, a new visuo-haptic interface for remediation of dysgraphic children. In First joint Eurohaptics conference and symposium on haptic interfaces for virtual environment and teleoperator systems: World haptics conference (pp. 411419), IEEE. https://doi.org/10.1109/WHC.2005.125

Herodotou, C. (2018). Young children and tablets: A systematic review of effects on learning and development. Journal of Computer Assisted Learning, 34, 1-9. https://doi.org/10.1111/jcal.12220

Hillman, M., \& Marshall, J. (2009). Evaluation of digital media for emergent literacy. Computers in the Schools, 26(4), 256-270. https://doi.org/10.1080/07380560903360186

Hingle, M., \& Kunkel, D. (2012). Childhood obesity and the media. Pediatric Clinics, 59(3), 677-692. https://doi.org/10.1016/j.pcl.2012.03.021

Hino, Y., \& Lupker, S. J. (1996). Effects of polysemy in lexical decision and naming: An alternative to lexical access accounts. Journal of Experimental Psychology: Human Perception and Performance, 22(6), 1331-1356. https://doi.org/10.1037/0096-1523.22.6.1331

Hisrich, K., \& Blanchard, J. (2009). Digital media and emergent literacy. Computers in the Schools, 26(4), 240-255. https://doi.org/10.1080/07380560903360160

Hnatiuk, J. A., Salmon, J., Hinkley, T., Okely, A. D., \& Trost, S. (2014). A review of preschool children's physical activity and sedentary time using objective measures. American Journal of Preventive Medicine, 47(4), 487-497. https://doi.org/10.1016/j.amepre.2014.05.042

Inkster, M., Wellsby, M., Lloyd, E., \& Pexman, P. M. (2016). Development of embodied word meanings: Sensorimotor effects in children's lexical processing. Frontiers in Psychology, 7, 317. https://doi. org/10.3389/fpsyg.2016.00317

James, K. H., \& Engelhardt, L. (2012). The effects of handwriting experience on functional brain development in pre-literate children. Trends in Neuroscience and Education, 1(1), 32-42. https://doi.org/ 10.1016/j.tine.2012.08.001

Kabali, H. K., Irigoyen, M. M., Nunez-Davis, R., Budacki, J. G., Mohanty, S. H., Leister, K. P., \& Bonner, R. L. (2015). Exposure and use of mobile media devices by young children. Pediatrics, 136(6), 1044-1050. https://doi.org/10.1542/peds.2015-2151

Kiefer, M., Schuler, S., Mayer, C., Trumpp, N. M., Hille, K., \& Sachse, S. (2015). Handwriting or typewriting? The influence of pen-or keyboard-based writing training on reading and writing 
performance in preschool children. Advances in Cognitive Psychology, 11, 136-146. https://doi.org/ 10.5709/acp-0178-7

Kiefer, M., \& Trumpp, N. M. (2012). Embodiment theory and education: The foundations of cognition in perception and action. Trends in Neuroscience and Education, 1(1), 15-20. https://doi.org/10. 1016/j.tine.2012.07.002

Kontra, C., Goldin-Meadow, S., \& Beilock, S. L. (2012). Embodied learning across the life span. Topics in Cognitive Science, 4(4), 731-739. https://doi.org/10.1111/j.1756-8765.2012.01221.x

Kotrla Topić, M., Šakić Velić, M., \& Merkaš, M. (2020). Tablet and Smartphone or a Book: The struggle between digital media and literacy environment in homes of croatian preschool children and its effect on letter recognition. Cyberpsychology, Behavior, and Social Networking, 23(6), 412-417. https://doi.org/10.1089/cyber.2019.0482

Lau, E., \& Lee, K. (2020). Parents' views on young children's distance learning and screen time during COVID-19 class suspension in Hong Kong. Early Education and Development. https://doi.org/10. 1080/10409289.2020.1843925

Lauricella, A. R., Wartella, E., \& Rideout, V. J. (2015). Young children's screen time: The complex role of parent and child factors. Journal of Applied Developmental Psychology, 36, 11-17. https://doi.org/10.1016/j.appdev.2014.12.001

Levy, R. (2009). 'You have to understand words... but not read them': Young children becoming readers in a digital age. Journal of Research in Reading, 32(1), 75-91. https://doi.org/10.1111/j. 1467-9817.2008.01382.x

Li, H., \& Rao, N. (2000). Parental influences on Chinese literacy development: A comparison of preschoolers in Beijing, Hong Kong, and Singapore. International Journal of Behavioral Development, 24(1), 82-90. https://doi.org/10.1080/016502500383502

Li, Y., Wang, R., \& Mo, L., (2007). Foudingju lijiezhong zhijue fangzhen de dongtai guocheng [The dynamic process of perceptual simulation in the comprehension of negative sentences]. Psychological Science, 30(4), 791-795. http://en.cnki.com.cn/Article_en/CJFDTotal-XLKX200704006. htm

Lissak, G. (2018). Adverse physiological and psychological effects of screen time on children and adolescents: Literature review and case study. Environmental Research, 164, 149-157. https:// doi.org/10.1016/j.envres.2018.01.015

Liu, D., Li, H., \& Wong, K. S. R. (2017). The anatomy of the role of morphological awareness in Chinese character learning: The mediation of vocabulary and semantic radical knowledge and the moderation of morpheme family size. Scientific Studies of Reading, 21(3), 210-224. https://doi. org/10.1080/10888438.2017.1278764

Liu, P. D., \& McBride-Chang, C. (2010). What is morphological awareness? Tapping lexical compounding awareness in Chinese third graders. Journal of Educational Psychology, 102(1), 62-73. https://doi.org/10.1037/a0016933

Loeffler, J., Raab, M., \& Cañal-Bruland, R. (2016). A lifespan perspective on embodied cognition. Frontiers in Psychology, 7, 845. https://doi.org/10.3389/fpsyg.2016.00845

Louwerse, M. M. (2018). Knowing the meaning of a word by the linguistic and perceptual company it keeps. Topics in Cognitive Science, 10(3), 573-589. https://doi.org/10.1111/tops.12349

Louwerse, M. M., \& Jeuniaux, P. (2010). The linguistic and embodied nature of conceptual processing. Cognition, 114(1), 96-104. https://doi.org/10.1016/j.cognition.2009.09.002

Luke, S. G. (2017). Evaluating significance in linear mixed-effects models in R. Behavior Research Methods, 49(4), 1494-1502. https://doi.org/10.3758/s13428-016-0809-y

Madigan, S., Browne, D., Racine, N., Mori, C., \& Tough, S. (2019). Association between screen time and children's performance on a developmental screening test. JAMA Pediatrics, 173(3), 244250. https://doi.org/10.1001/jamapediatrics.2018.5056

McBride-Chang, C., \& Chen, H. C. (Eds.). (2003). Reading development in Chinese children. Praeger Publishers.

McBride-Chang, C., Lin, D., Liu, P. D., Aram, D., Levin, I., Cho, J. R., Shu, H., \& Zhang, Y. (2012). The ABC's of Chinese: Maternal mediation of Pinyin for Chinese children's early literacy skills. Reading and Writing, 25(1), 283-300. https://doi.org/10.1007/s11145-010-9270-y

McManis, L. D., \& Gunnewig, S. B. (2012). Finding the education in educational technology with early learners. Young Children, 67(3), 14-24.

Minogue, J., \& Jones, M. G. (2006). Haptics in education: Exploring an untapped sensory modality. Review of Educational Research, 76(3), 317-348. https://doi.org/10.3102/00346543076003317 
Neumann, M. M. (2014). An examination of touch screen tablets and emergent literacy in Australian pre-school children. Australian Journal of Education, 58(2), 109-122. https://doi.org/10.1177/ 0004944114523368

Neumann, M. M. (2018). Parent scaffolding of young children's use of touch screen tablets. Early Child Development and Care, 188(12), 1654-1664. https://doi.org/10.1080/03004430.2016. 1278215

Paivio, A. (2010). Dual coding theory and the mental lexicon. The Mental Lexicon, 5(2), 205-230. https://doi.org/10.1075/ml.5.2.04pai

Pate, R., McIver, K., Dowda, M., Brown, W., \& Addy, C. (2008). Directly observed physical activity levels in preschool children. Journal of School Health, 78(8), 438-444. https://doi.org/10.1111/j. 1746-1561.2008.00327.x

Pecher, D., \& Zwaan, R. A. (Eds.). (2005). Grounding cognition: The role of perception and action in memory, language, and thinking. Cambridge University Press.

Pexman, P. M., Hargreaves, I. S., Edwards, J. D., Henry, L. C., \& Goodyear, B. G. (2007). Neural correlates of concreteness in semantic categorization. Journal of Cognitive Neuroscience, 19(8), 14071419. https://doi.org/10.1162/jocn.2007.19.8.1407

Plaut, D. C., \& Shallice, T. (1993). Perseverative and semantic influences on visual object naming errors in optic aphasia: A connectionist account. Journal of Cognitive Neuroscience, 5(1), 89-117. https:// doi.org/10.1162/jocn.1993.5.1.89

Pritzker, S. (2003). The role of metaphor in culture, consciousness, and medicine: A preliminary inquiry into the metaphors of depression in Chinese and Western medical and common languages. Clinical Acupuncture and Oriental Medicine, 4(1), 11-28. https://doi.org/10.1016/S1461-1449(02)00013-0

$\mathrm{R}$ Core Team (2020). R: A language and environment for statistical computing. R Foundation for Statistical Computing. https://www.R-project.org/

Raven, J. (1996). The Raven's progressive matrices: Change and stability over culture and time. Cognitive Psychology, 41(1), 1-48. https://doi.org/10.1006/cogp.1999.0735

Sadoski, M., \& Paivio, A. (2004). A dual coding theoretical model of reading. In R. B. Ruddell \& N. J. Unrau (Eds.), Theoretical models and processes of reading (5th ed., pp. 1329-1362). International Reading Association.

Schilhab, T. S., Stevenson, M. P., \& Bentsen, P. (2018). Contrasting screen-time and green-time: A case for using smart technology and nature to optimize learning processes. Frontiers in Psychology, 9, 773. https://doi.org/10.3389/fpsyg.2018.00773

Schönborn, K. J., Bivall, P., \& Tibell, L. A. (2011). Exploring relationships between students' interaction and learning with a haptic virtual biomolecular model. Computers and Education, 57(3), 20952105. https://doi.org/10.1016/j.compedu.2011.05.013

Shamir, A., \& Korat, O. (2007). Developing an educational e-book for fostering kindergarten children's emergent literacy. Computers in the Schools, 24(1-2), 125-143. https://doi.org/10.1300/J025v 24n01_09

Shen, H. H., \& Bear, D. R. (2000). Development of orthographic skills in Chinese children. Reading and Writing, 13(3), 197-236. https://doi.org/10.1023/A:1026484207650

Siakaluk, P. D., Pexman, P. M., Aguilera, L., Owen, W. J., \& Sears, C. R. (2008a). Evidence for the activation of sensorimotor information during visual word recognition: The body-object interaction effect. Cognition, 106(1), 433-443. https://doi.org/10.1016/j.cognition.2006.12.011

Siakaluk, P. D., Pexman, P. M., Sears, C. R., Wilson, K., Locheed, K., \& Owen, W. J. (2008b). The benefits of sensorimotor knowledge: Body-object interaction facilitates semantic processing. Cognitive Science, 32(3), 591-605. https://doi.org/10.1016/j.cognition.2006.12.011

Sigrist, R., Rauter, G., Riener, R., \& Wolf, P. (2013). Augmented visual, auditory, haptic, and multimodal feedback in motor learning: A review. Psychonomic Bulletin and Review, 20, 21-53. https://doi.org/ 10.3758/s13423-012-0333-8

Skulmowski, A., Pradel, S., Kühnert, T., Brunnett, G., \& Rey, G. D. (2016). Embodied learning using a tangible user interface: The effects of haptic perception and selective pointing on a spatial learning task. Computers and Education, 92-93, 64-75. https://doi.org/10.1016/j.compedu.2015.10.011

Smith, L., \& Gasser, M. (2005). The development of embodied cognition: Six lessons from babies. Artificial Life, 11(1-2), 13-29. https://doi.org/10.1162/1064546053278973

Sousa, M. J., \& Rocha, Á. (2019). Digital learning: Developing skills for digital transformation of organizations. Future Generation Computer Systems, 91, 327-334. https://doi.org/10.1016/j.future.2018. 08.048 
Sweetser, P., Johnson, D., Ozdowska, A., \& Wyeth, P. (2012). Active versus passive screen time for young children. Australasian Journal of Early Childhood, 37(4), 94-98. https://doi.org/10.1177/ 183693911203700413

Tandon, P. S., Zhou, C., Sallis, J. F., Cain, K. L., Frank, L. D., \& Saelens, B. E. (2012). Home environment relationships with children's physical activity, sedentary time, and screen time by socioeconomic status. International Journal of Behavioral Nutrition and Physical Activity, 9(1), 1-9. https:// doi.org/10.1186/1479-5868-9-88

Tillotson, S. M., Siakaluk, P. D., \& Pexman, P. M. (2008). Body-object interaction ratings for 1618 monosyllabic nouns. Behavior Research Methods, 40(4), 1075-1078. https://doi.org/10.3758/BRM.40.4. 1075

Tousignant, C., \& Pexman, P. M. (2012). Flexible recruitment of semantic richness: Context modulates body-object interaction effects in lexical-semantic processing. Frontiers in Human Neuroscience, 6 , 53. https://doi.org/10.3389/fnhum.2012.00053

van der Kooy-Hofland, V. A., van der Kooy, J., Bus, A. G., van Ijzendoorn, M. H., \& Bonsel, G. J. (2012). Differential susceptibility to early literacy intervention in children with mild perinatal adversities: Short-and long-term effects of a randomized control trial. Journal of Educational Psychology, 104(2), 337-349. https://doi.org/10.1037/a0026984

Wang, R. M., Mo, L., Wang, L.L., \& Wu, J. (2005). Yanyu lijiezhong de zhijue fuhao biaozheng yu mingti fuhao biaozheng [Perceptual symbol representation and propositional symbol representation in language comprehension]. Acta Psychologica Sinica, 2(37), 143-150. http://en.cnki.com.cn/Artic le_en/CJFDTOTAL-XLXB200502000.htm

Wang, G., Zhang, J., Lam, S., Li, S., Jiang, Y., Sun, W., Chan, N., Kong, A., Zhang, Y., Li, S., Li, A., Jiang, F., Shen, X., \& Wing, Y. (2019). Ten-year secular trends in sleep/wake patterns in Shanghai and Hong Kong school-aged children: A tale of two cities. Journal of Clinical Sleep Medicine, 15(10), 1495-1502. https://doi.org/10.5664/jcsm.7984

Wellsby, M., \& Pexman, P. M. (2014). Developing embodied cognition: Insights from children's concepts and language processing. Frontiers in Psychology, 5, 506. https://doi.org/10.3389/fpsyg.2014.00506

Wellsby, M., Siakaluk, P. D., Owen, W. J., \& Pexman, P. M. (2011). Embodied semantic processing: The body-object interaction effect in a non-manual task. Language and Cognition, 3(1), 1-14. https:// doi.org/10.1515/langcog.2011.001

Williams, L. E., Huang, J. Y., \& Bargh, J. A. (2009). The scaffolded mind: Higher mental processes are grounded in early experience of the physical world. European Journal of Social Psychology, 39(7), 1257-1267. https://doi.org/10.1002/ejsp.665

Wilson, M. (2002). Six views of embodied cognition. Psychonomic Bulletin and Review, 9(4), 625-636. https://doi.org/10.3758/BF03196322

Yu, N. (2002). Body and emotion: Body parts in Chinese expression of emotion. Pragmatics and Cognition, 10(1-2), 341-367. https://doi.org/10.1075/pc.10.12.14yu

Yu, N. (2009). From body to meaning in culture: Papers on cognitive semantic studies of Chinese. Berlin: John Benjamins Publishing Company.

Publisher's Note Springer Nature remains neutral with regard to jurisdictional claims in published maps and institutional affiliations. 